\title{
POSTURAL KONTROL VE SPOR: KASSAL YORGUNLUK VE POSTURAL KONTROL İIŞKISİ
}

\author{
Deniz ŞIMŞEK ${ }^{1} \quad$ Hayri ERTAN ${ }^{1}$
}

Geliş Tarihi: 19.8.2011

Kabul Tarihi: 22.12.2011

\section{ÖZET}

Denge, atıcılık gibi statik spor branşlarında ve futbol, jimnastik, güreş gibi maksimum çeviklik gerektiren dinamik sporlarda, spor performansı açısından oldukça büyük öneme sahiptir. Denge, istemli hareket öncesinde, sırasında ve sonrasında postural ayarlamalar ile stabilite durumunu tekrar kazanmak için, stabilizasyonu bozan durumlara ve eksternal pertürbasyonlara karşı hızlı ve etkili bir şekilde reaksiyon gösterebilme yeteneği olarak tanımlanmaktadır. Ayrıca denge, içsel ve dışsal güçlerin ve çevreyi içeren faktörlerin dinamik integresyonu tarafından sürdürülmektedir. Dışsal (kaygan zemin üzerinde yürümek, ışık değişimi vb.) ve içsel denge perturbasyonlarına [kas sertliği (stiffness), kas iskelet yaralanmaları ve yorgunluk gibi] karşı dik duruş pozisyonunun devam ettirilebilmesi; sensör (somatosensör, görsel ve vestibular) ve motor sistemin entegresyonunu gerektirmektedir. İçsel perturbasyonlara maruz kalınan durumlarda postural salınımın belirlenmesine yönelik gerçekleştirilmiş çalışmalar bulunmaktadır. Bu çalışmalar incelendiğinde en genel içsel perturbasyon postural kontrol paradigmaları; (a) başın hareketini, (b) gözlerin kapalı olduğu durumları, (c) içsel odaklanma durumunu ve (d) kassal yorgunluğu içermektedir. Egzersiz sonrasında dengeyi bozan ya da kötüleştiren temel faktör olarak ifade edilen yorgunluk; eklemlerin proprioseptif ve kinestetik özelliklerini zayıflatarak kas iğciğinin deşarj olma eşiğini arttırmaktadır. Bu durum afferent geribildirimi olumsuz etkileyerek eklem farkındalığında istenmeyen değişimlere neden olmaktadır. Bu bağlamda, kassal yorgunluk; periferal proprioseptif sistemi, merkezi propriosepsiyon sürecini ve aynı zamanda kuvvet üretim kapasitesini değiştirdiği bilinen fiziksel, profesyonel ya da rekreasyonel aktivitelerin kaçınılmaz bir fenomenini sunmaktadır. Bu çalışmada, farklı egzersiz formlarının postural kontrol üzerinde ne gibi etkilerinin olduğunu ortaya koyan araştırmalara yer verilecektir.

Anahtar Kelimeler: Postür, Postural Kontrol, Kassal Yorgunluk.

\section{POSTURAL CONTROL AND SPORT: MUSCULAR FATIGUE AND POSTURAL CONTROL RELATIONSHIP}

\begin{abstract}
Balance is one of the most importante factors effecting static sport branches like shooting, archery etc. and dynamic sports branches such as football, gymnastics and wrestling that require agility. Balance is required to regain stability condition before, during and after voluntary movement with the postural adjustments. Therefore, balance has been defined as the ability to show quick and effective reactions against stabilization distorting and external perturbating situations. In addition, balance is carried out by dynamic integration of internal and external forces and factors, which is including the environment. The maintainance of the upright posture against to external (to walk on slippery floors, light replacement, etc.) and internal (such as; muscle stiffness, skeletal and muscle injuries, and fatigue) balance perturbations require the integration of sensors (somatosensory, visual and vestibular) and motor system. There have been some studies, which have been performed to investigate postural sway at internal perturbations situations. When these studies examined the general internal control of postural perturbation paradigms including: (a) the movement of head (b) eyes closed states, (c) the status of the internal focus, and (d) muscular fatigue. The fatigue, which is a disrupt or broke of balance after exercise increases of discharge threshold of muscle spindle to weakening proprioception and kinesthetic properties of joint, has been defined as a main factor on postural control. This situation leads to adverse changes from joint awareness of negatively affecting the afferent feedback. Also, muscular fatigue offers inevitable phenomenon of the physical, professional or recreational activities that are also known to alter peripheral proprioceptive system and the central process of proprioception and force production capacity. In this study, a literature review will be made on the effects of different forms of exercise on postural control.
\end{abstract}

Keywords: Posture, Postural Control, Muscular Fatigue.

\footnotetext{
1 Anadolu Üniversitesi Beden Eğitimi ve Spor Yüksekokulu, Eskişehir.
} 


\section{Yorgunluk ve Yorgunlukla İlişkili Faktörler}

Yorgunluk hem fizyolojik hem de psikolojik faktörleri içeren çok karmaşık bir kavramdır. Bu nedenle yorgunluk tek bir kavram ya da süreç olarak ele alınamamaktadır. Aksine, hem santral sinir sistemi hem de kas içinde birden fazla rol alan, çok farklı komponentleri içeren bir olaydır (1). Bu karmaşık süreç sonucunda ortaya çıkan yorgunluk, kasların ortaya çıkardığı kuvvet ve güç yeteneğini azaltmaktadır. Gandevia'ya (2001) göre başlangıçtaki maksimal gücü sürdürmedeki başarısızlık sinir stimülasyonunun distal noktasında meydana gelen periferal yorgunluğa (nöro-muskular bağlantıdaki başarısızlık) ve kasların istemli olarak aktive edilmesindeki başarısızlıkla sonuçlanan merkezi yorgunluğa (motor nöronlara drive başarısızlığı) bağlıdır. Periferal velya da merkezi kas yorgunluğu, metabolik velya da nörojenik değişimlere ve nöromuskular kontroldeki kötüleşmeye neden olmaktadır.

Periferal yorgunluk kas düzeyinde gerçekleşmektedir ve her biri farklı zaman etkisine sahip iki mekanizmanın sonucu olabileceği varsayılmaktadır. Birinci tip periferal yorgunluk kaslardaki metabolik değişimlerle ilişkilidir. Kasılan kaslardaki ATP depolarının boşalması ve kasların pH düzeyinin azalması (artan laktat konsantrasyonu ve hidrojen iyonu) sonucu meydana gelmektedir. Genellikle kısa ömürlü olan bu etkiler büyük ölçüde egzersizin sonlanmasını takiben birkaç dakika içinde ortadan kaybolmaktadır. İkincisi ve daha uzun süreli sonlanan, kas fibrillerinin kasılma mekanizmasının sayılarca komponentinin başarısızlığından kaynaklanan periferal kassal yorgunluğun sebepleridir. Kasılan kaslara azalan nöral sürüşten (drive) kaynaklanan merkezi yorgunluk durumu da mümkündür (2) ve bu durum genellikle uzun süreli egzersiz (örneğin birkaç saatlik egzersiz nöbetleri) sonucu ortaya çıkmaktadır $(3,4)$.

\section{Postural Kontrol ve Postural Kontrol Kasları Üzerine Yorgunluğun Etkileri}

Postural kontrol, vücudun sürekli dengeyi bozucu güçlerle mücadele ederek ağırlık merkezinin destek noktası sınırları içerisinde devam ettirebilme yeteneği olarak ifade edilmektedir (5). Hem fonksiyonel hem de performans temelli olan postural kontrol ya da denge; vücut ağırlık merkezini koruyabilmek için eklem, kas, görsel ve işitsel reseptörlerin koordine edilmiş aktivasyonunu gerektirmektedir. Deri, eklem kapsülü, ligamentler ve kas iğciklerini içeren birkaç kaynaktaki sensör girdi postural kontrolün korunmasına katkı sağlayarak birtakım değişikliklere neden olmaktadır (6, 7).

Sakin bir duruşu sırasında, Merkezi Sinir Sistemi'nin (MSS) ayrlamaları sayesinde postural kaslarda normal olarak çok az bir aktivite söz konusudur (8). Ancak, herhangi bir perturbasyon sonucunda vücut salınımında artış ortaya çıkmaktadır. Vücut salınımındaki artış sonucu, dengeyi muhafaza edebilmek için kas aktivitesinde de eş zamanlı artışlar ortaya çıkmaktadır (9). Ancak, duyusal girdilerin olası değişim rolleri dışında, bazı özel fizyolojik koşullar altında da vücut denge kontrolü etkilenebilmektedir. Örneğin, sportif aktiviteler sırasında kardiyovasküler değişimler (10-14), endokrinal etkiler (15) ve enerji kaynaklarının kullanımındaki değişimler (16) sonucu ortaya çıkan yorgunluk durumu postural kontrol üzerinde bir takım etkilere neden olmaktadır. Bu nedenle araştırmacılar postural kontrol üzerine yorgunluğun ne gibi etkileri olabileceği konusunda odaklanmaktadır. Gerçekleştirilen birçok araştırmada ayakta duruş sırasında postür kasları üzerine yorgunluğun etkileri araştırılmaktadır. Bu araştırmalarda genellikle, kassal yorgunluğun postural kontrolü kötüleştirici etkileri olduğu bildirilmiştir (17-22). Gerçekleştirilen çalışmalarda nispeten kısa süreli egzersizler boyunca yorgunluğun tetiklenmesi üzerine odaklanmışlardır. Postür ve denge çalışmalarında kullanılan iki yaygın yorgunluk protokolünde submaksimal ile maksimal kassal kasılmalar $(6,23)$ ya da submaksimal ile maksimal aerobik egzersizler tekrarlanmaktadır $(6,24-28)$. Araştırmaların sonucunda, kassal yorgunluğun bir sonucu olarak, postural salınımda artışlar gözlenmiştir. Ayrıca, koşu, bisiklet, triatlon, biatlon gibi spor branşlarının neden olduğu kas yorgunluğu, postural stabilite üzerinde negatif etkiye sahiptir. Bu etki, motor birim velya da merkezi sürüş karakteristiklerinin davranışlarında değişimlere sebep olmaktadır $(26,29-33)$. Ayrıca gerçekleştirilen tüketici fiziksel aktiviteler; (1) proprioseptif ve ekstroseptif informasyonu velya da integresyonu kötüleştirmekte velya da kassal sistemin etkinliğini azaltmakta, (3) tip III ve IV kas affentlerinin motor-nöron çıktılarını ya da duyarlığını azaltmakta, ayrıca (4) yorgunluk verici egzersizler sonrasında örneğin alt ekstremite eklem açısının tekrar aynı açıyı yakalama yeteneğini olumsuz etkilemektedir (29, 30, 32-35). Yorgunluk durumuna tepki olarak ise kinestetik farkındalık ve motor kontrolde azalmalar meydana gelmektedir (36).

Postural tonik kasları içerisinde yer alan kasların (ayak bileği plantar fleksöri ve dorsifleksöri, ayak bileği invertörleri ve evertörleri, diz ekstansörleri, kalça fleksör-ekstansörleri, kalça abduktor-adduktörleri, erektör spina) güçlü bir şekilde katılımını gerektiren basit segmental hareketlerin neden olduğu yorgunluk durumunun postural kontrolün devam ettirilmesinde önemli etkileri olduğu ifade edilmektedir (6, 18, 20, 23, 24, 37-44). Örneğin, ayak bileği yorgunluğunun postural kontrol üzerine etkileri incelenmiştir (4, 18, 19, 23, 24, 27, 37, 42). Postural kontrol üzerine yorgunluk etkilerinin süresi, alt ekstremite yorgunluğu için yorucu egzersiz kesildikten sonra 10-20 dk arasında değişkenlik göstermektedir. Gerçekleştirilen az sayıda çalışmada aerobik egzersiz (bisiklet ve koşu gibi) sonucu gelişen yorgunluğun postural kontrol üzerindeki etkileri analiz edilmiştir ve Gribble ve Hertel (2004) tarafından kalça kasının postürün korunmasındaki rolünü ortaya koyan çalışma gerçekleştirilmiştir. Araştırma sonucu, kalça kaslarının yorgunluğunun postural kontrolü kötüleştirdiği yönündedir. Salavati ve ark. (2007), ayak bileği kas yorgunluğunun kalça kas yorgunluğuna göre postural kontrolü daha fazla bozduğunu ifade etmektedir. Dickin ve Doan (2008) ise diz kasları ve ayak bileği kaslarının postural kontrol üzerindeki yorgunluk etkileri açısından bir farklılık olmadığını ifade etmektedir. Bu çalışmalara ek olarak, degenin sağlanmasında diz kaslarının katkısını vurgulayan çalışmalar da mevcuttur (2). Gribble ve Hertel'in (2004) araştırma bulguları diz ekleminin yorgunluğunun ayak bileği ekleminin yorgunluğundan daha büyük 
ŞimŞEK, D., ERTAN, H.,“Postural Kontrol ve Spor: Kassal Yorgunluk ve Postural Kontrol lilşkisi”

stabilite kaybı ile sonuçlandığını kanıtlamaktadır. Çetin ve ark., (2008) alt ekstremite ve gövde kas yorgunluğunun statik ve dinamik denge üzerine etkisini araştırdıkları çalışmalarında, yorgunluk öncesi ve yorgunluk sonrası gövde ve alt ekstremite kasları ve statik denge skorları arasında önemli farklılıklar bulmuşlardır. Araştırma bulguları dengenin genel olarak alt ekstremite ve gövde kaslarının yorgunluğundan etkilendiğini göstermektedir. Ancak statik denge kontrolünün dinamik denge kontrolünden daha fazla etkilendiği ifade edilmektedir. Bu araştırmalarda; yerçekim merkezi (COM) ya da basınç merkezi (COP) yörüngesi ölçümünde postural salınımda artışlar gözlenmiştir ki, bu durum postural kontrol ve postural stabilitede değişimlere ya da düşme riskine işaret etmektedir (47). Bunun yanı sıra yorgunluk, günlük yaşam ya da spor ortamında kas-iskelet yaralanma riskini ciddi bir şekilde arttırmaktadır. Kas yaralanmalarının önlenmesi açısından bu sonuçların farklı egzersiz formları ya da rehabilitasyon sırasında dikkate alınması önem taşımaktadır.

\section{Farklı Egzersiz Formları ile Oluşan Yorgunluğun Postural Kontrol Üzerine Etkileri}

Postür ve dengenin, statik veya dinamik koşullar altında devam ettirilmesi ve kontrolü, hem statik hem de dinamik fiziksel aktiviteler için önem taşımaktadır. Gerçekleştirilen egzersizler sonrasında postural kontrolde birtakım değişimler gözlenmektedir. Postural salınımda meydana gelen bu değişimler; egzersizin tipine, şiddetine, süresine bağlı olduğu gibi farklı tip egzersizlerin neden olduğu proprioseptif uyarının şiddetinden de (sıçramalar, kalf yükselmeleri vb.) kaynaklanmaktadır. Örneğin postural parametrelerde meydana gelen bozulmaların (kötüleşmeler) (a) koşu sırasında yürüyüşten $(3,48)$, (b) yürüyüş sırasında bisikletten (29), (c) kısa süreli-yoğun egzersizler sırasında uzun süre devam eden egzersizlerden (49) daha fazla meydana geldiği gözlenmiştir. Ayrıca, farklı kas kasılma formuna sahip ve kas fibrillerinin farklı aktivasyonuna neden olan egzersizlerden sonra postural salınımda farklılıklar gözlenmektedir. Yorgunluğun postural kontrolü negatif yönde etkilediğini gösteren birçok çalışma mevcuttur (19, 30, 38, 50). Gerçekleştirilen bu araştırmaların birkaçında performans üzerine yorgunluğun etkileri BESS (Balance Error Scoring System) ile değerlendirilmiştir. Crowell ve ark. (2001), squat sıçrama, sprint ve koşu bandında gerçekleştirilen koşu sonrasında postural stabilitede azalmalar saptamışlardır. Benzer şekilde, Wilkins ve ark. (2004), 7-istasyonlu, 20 dk'dan oluşan egzersiz protokolü sonrasında postural stabilite değerlerini BESS ile ölçmüşler ve postural stabilite değerlerinde azalma kaydetmişlerdir. Gerçekleştirilen bu iki çalışmada da araştırılan yorgunluk aerobik ve anaerobik aktivitenin bir fonksiyonudur ve yorgunluğa neden olan etki tam olarak açık değildir.

Zachary ve ark. (2008), sağlıklı kollej sporcularında (cinsiyet: kadın=18, erkek=18; yaş: $19.00 \pm 1.01$ yıl; boy: $172.44 \pm 10.47 \mathrm{~cm}$; vücut kitle indeksi: $69.72 \pm 12.84 \mathrm{~kg}$ ) aerobik ve anaerobik egzersiz protokolü uygulayarak her bir protokolün dinleme zamanından hemen sonra postural stabilite ölçümleri gerçekleştirmişlerdir. Aerobik ve anaerobik egzersiz protokolü sonucu oluşan yorgunluğun postural kontrol üzerindeki etkilerini değerlendirdikleri çalışmada CB (counter balance) kullanarak tekrarlı ölçümler gerçekleştirilmiştir. Katılımcılar 7 gün içinde 2 CB oturumuna katılmıştır. Her bir oturum 1 egzersiz protokolünden oluşmuş, temel ölçümleri ilk oturumda alınmış ve egzersiz sonrasında 3., 8., 13., ve 18. dk'larda gerçekleştirilen postural kontrol ölçümleri ile devam etmiştir. Ölçümler BESS ile gerçekleştirilmiştir. Araştırmanın bulguları tüm ölçümlerde her bir egzersiz protokolü sonrasında postural kontrolde azalma olduğunu göstermektedir. Ayrıca, her iki egzersiz protokü için tüm postural kontrol ölçümleri [COP ortalama salınım hızı, (SV) ve eliptik salınım alanı (ESA)] 13 dk içinde başlangıç değerine geri dönmüştür. Bu bağlamda, sarfedilen eforun etkisinin her bir egzersiz oturumunun tamamlanmasından $13 \mathrm{dk}$ sonrasında sonlandığı ifade edilebilir. Araştırma sonucuna göre; BESS tarafından gerçekleştirilen aerobik ve enaerobik egzersiz protokolü sonrasında postural kontrol negatif etkilenmektedir. Bu bulgular doğrultusunda, antrenörlerin ve diğer klinisyenlerin bu etkileri dikkate alarak postural kontrolün değerlendirilmesi için uygun süreyi belirlemelerinde yardımcı olabileceği ifade edilebilir.

Yukarıda ifade edilen çalışmada aerobik ve anaerobik egzersiz protokolü sonrasında postural kontrol parametrelerinin başlangıç değerlerine dönüş süreleri incelenmiştir. Ancak, aynı kalp atım hızında ve farklı enerji kullanımının gerçekleştirildiği egzersiz protokolleri de postural kontrol üzerinde farklı etkiler yaratabilmektedir. Örneğin, Zemkova ve Hamar, (2003); aynı kalp atım hızına neden olan fakat farklı enerji üretiminde gerçekleştirilen egzersizler sonrasında denge parametrelerini karşılaştırmışlardır. Bir grup beden eğitimi öğrencisi farklı günlerde, 2 farklı bisiklet ergometresi testi gerçekleştirmişlerdir. İlk testte başlangıç şiddeti olan 100 watt her bir dk da 20 watt attırılmıştır. İkinci testte başlangıç şiddeti olan 100 watt sürekli aynı şiddette devam etmiştir. Her iki test, katılımcıların kalp atım hızları 160 atımldk değerine ulaştığında sonlandırılmıştır. Bu testlerin ortalama süresi sırasıyla $8 \mathrm{dk}$ ve $1.5 \mathrm{dk}$ dır. Sonuçlar, kısa süreli-yoğun egzersizden $(6.8 \pm 0.8 \mathrm{~mm} / \mathrm{sn}$ den $25.4 \pm 3.4 \mathrm{~mm} / \mathrm{sn}$ 'ye $)$ sonraki ilk 5 sn'deki COP hızı giderek artan egzersizden ( $6.4 \pm 0.7 \mathrm{~mm} / \mathrm{sn}$ den $14.7 \pm 2.7 \mathrm{~mm} / \mathrm{sn}$ 'ye) daha fazla yükselmiştir. Ancak, dinlenmenin 2 . dk'sının son 5 sn'lik periyodunda her iki egzersiz sonrası COP hızında önemli farklılık (sırasıyla; $9.2 \pm 1.3 \mathrm{~mm} / \mathrm{sn}$ ve $8.7 \pm 1.1 \mathrm{~mm} l \mathrm{sn}$ ) bulunmamıştır. Egzersiz sonrası postural stabilitede ortaya çıkan bu farklılıklar; kısa süreli-yoğun egzersiz sonucunda giderek artan egzersiz protokolüne göre daha yüksek kan laktat değerlerinin ortaya çıkmasından kaynaklanmaktadır (kan laktat değerleri sırasıyla; $8.8 \pm 1.4 \mathrm{~mm} / \mathrm{sn}$ ve $4.9 \pm 0.7 \mathrm{mmlsn}$ ). Şiddetli egzersiz sonrasında ortaya çıkan daha yüksek kan laktat değerleri daha yüksek oksijen borçlanmasını da beraberinde getirmektedir. Daha yüksek oksijen borçlanması ise daha yüksek ventilasyona ve kalp atım hızına neden olmaktadır. Bu bağlamda, yoğun egzersizin neden olduğu anaerobik asidozun kompansasyonunun bir sonucu olarak daha derin ventilasyon; daha uzun-yavaş egzersizle karşılaştırıldığında postural stabilitede daha büyük bozulmaya neden olmaktadır. Bu bulgular birkaç araştırmacının bulguları ile de tutarlılık göstermektedir (53-56). 
Hiperventilasyonun, yorgunluğa bağlı olarak postural kontrol üzerindeki olumsuz etkilerinin yanı sıra, 25 km koşu gibi uzun süreli egzersizler (30) ya da 1 saat $44 \mathrm{dk}$ bisiklet egzersizlerinin (31) postural kontrol üzerine etkilerini gösteren araştırmalar da mevcuttur. Nagy ve ark.'nın (2004) triatloncularla gerçekleştirdiği araştırma da bu araştırmalar arasında yer almaktadır. Uzun mesafe triatlon yarışı (ironman triathlon) sırasıyla ve ara vermeksizin, $3.86 \mathrm{~km}$ yüzme, $180.25 \mathrm{~km}$ bisiklet ve $42.195 \mathrm{~km}$ koşudan oluşmaktadır. Bu nedenle bu yarışa katılan sporcular yüksek düzeyde koşu, bisiklet ve yüzme antrenmanları uygulamaktadırlar. Ancak, uzun mesafe triatlon antrenmanı özel olarak denge uygulamalarını gerektirmemekte ve bu nedenle bu sporcuların postural kontrollerinin, sağlıklı ve fiziksel olarak aktif bireylerden farklı olabileceği düşünülmektedir. Nagy ve ark. (2004) 10 erkek triatlon sporcusu ve fiziksel olarak aktif 10 kişiden oluşan kontrol grubuyla gerçekleştirdikleri çalışmada triatlon egzersizi sonrası postural salınım değerlerini karşılaştırmışlardır. Statik postural stabilite tek bir kuvvet platformu üzerinde dikilirken gözler açık ve kapalı olacak şekilde değerlendirilmiştir. Öncelikle, her iki grubun vücut salınımı kuvvet platformu üzerinde analiz edilmiş ve sonrasında sporculara triatlon antrenmanları yaptırılmıştır. Ölçümler yarış sonrasında tekrarlanmıştır. Deneklerin her iki yöndeki (A-P ve $M-L$ ) salınımının değerlendirilmesinde spektral analiz kullanılmıştır. Platform salınımının frekans spektrumu 0-0.3, 0.3-1 ve 1-3 Hz. intervalleri şeklinde Hızıı Fourier dönüşümü ile analiz edilmiştir. Her iki yöndeki salınım yolu ve toplam yol gözler kapalı olarak gerçekleştirilen ölçümlerde sporcularda kontrol grubuna göre daha düşük bulunmuştur. Gözler açık olarak gerçekleştirilen ölçümlerde kontrol grubunun her iki yöndeki salınımında artış gözlenirken, sporcu grubunda artış meydana gelmemiştir. Frekans analizinde, gözler kapalı gerçekleştirilen ölçümlerde medio-lateral yönlerde daha yüksek stabilite düzeyleri gözlenmiştir. Dayanıklılık yarışı hem toplam salınım yolunda (gözler kapalı) artışla sonuçlanmış hem de bu değişimler frekans bandında önemli derecede daha yüksek bulunmuştur. Bu sonuçlar, triatlon sporcularının daha iyi denge değerlerine sahip olduklarını ve postural kontrolün sağlanmasında görsel kaynağa daha az bağımlı olduklarını göstermektedir. Ayrıca, uzun mesafe yarışındaki ilerleyen proprioseptif stimülasyon, vestibüler ve görsel girdiler postural kontrolde önemli derecede bozulmalara neden olmaktadır. Bu sonuçlar neticesinde yarış sonrasında bozulan postural kontrol değerlerinin (1) kassal yorgunluğa, (2) sinir-kas yorgunluğuna, (3) merkezi ve duyusal zayıflamalara, (4) dehitratasyona, kardiyo-respiratuvar değişimlere ve ifade edilen tüm bu faktörlerinin birleşimiyle ortaya çıkan etkilere bağlı olabileceği ifade edilebilir.

Yorgunluk düzeyine bağlı olarak postural kontrol üzerinde etkisinin incelendiği bir diğer aktivite ise danstır. Aerobik ya da rock \& roll dansın yoğun sıçramaları sırasında soleus kasının kas iğciklerinin, tendon organlarının, eklem reseptörlerinin ve kutanöz mekanoreseptörlerinin uyarılması bu sensör kaynakların duyarlılıklarında azalmalara neden olmaktadır. Afferent impulslarda meydana gelen tam olmayan azalmalar dengenin proprioseptif geri bildirim kontrolünde bozulmalara (deterioration) neden olmaktadır. Ancak rock \& roll ve aerobik dans sırasındaki farklı şiddetteki kas kasılmaları farklı düzeyde proprioseptif uyarılma ortaya çıkaracağı için postural stabilite üzerinde farklı etkilerinin olabileceği düşünülmektedir. Zemkova ve ark. (2009), aynı süre ve şiddette (kalp atım hızı; yaklaşık 180 atımldk) gerçekleştirilen aerobik, rock \& roll ve eşli dans performansı sonrasında ortaya çıkan postural salınım değerlerini karşılaştırmışlardır. En şiddetli denge bozulmaları akrobatik hareketleri ve sıçrama egzersizlerini içerdiği için rock \& roll danstan sonra gözlenmiştir $(27.4 \pm 4.7 \mathrm{mmlsn})$. İkinci sırada aerobik performans $(24.6 \pm 4.5 \mathrm{~mm} / \mathrm{sn})$ ve son sırada daha rotasyonel egzersizleri içeren dans performansı (jive) $(21.0 \pm 3.8 \mathrm{~mm} / \mathrm{sn})$ yer almaktadır. Ayrıca, $1 \mathrm{dk}$ 'ık dinlenme sırasında denge ayarlamalarının hızındaki farklılıklar sırasıyla \% 39.8, \% 22.8 ve \% 22.5' tir. Egzersiz sonrasındaki denge bozulmalarına işaret eden bu bulguların gerçekleştirilen aktiviteye bağlı olduğu görülmektedir. Sıçrama sırasında proprioseptif uyarının şiddetinin yanı sıra gerçekleştirilen spor performansının karakteristiği denge bozulmalarının büyüklüğü ve dengenin tekrar sağlanabilme hızı hakkında önemli bir role sahiptir. Bu bağlamda, bu çalışma postural yanıtın genel ve alışıldık egzersiz metotları yerine spora özgü egzersizlerle değerlendirilmesinin önemini de ortaya koymaktadır.

\section{TARTIŞMA VE SONUÇ}

Duyu-motor süreç olarak postural kontrol dikkate alındığında (58), kassal yorgunluğun; periferik proprioseptif ve merkezi propriosepsiyon sistemi değiştirdiği bilinmektedir (35). Aynı zamanda kassal yorgunluk, sürecin hem duyu hem de motor yanını etkileyerek kuvvet-üretim kapasitesini de değiştirmektedir (59).

Kassal yorgunluk, tekrarlanan kas kasılması sonrasında gerim ve kuvvet çıktısındaki düşüş ile ilişki göstermektedir. Bu durum sadece kas düzeyindeki periferal değişimler sonucunda değil aynı zamanda merkezi sinir sisteminin motor nöronlara yeterli düzeyde motor sürüşü gerçekleştirmesindeki başarısızlıktan da kaynaklanmaktadır (2, 60). Bu nedenle kassal yorgunluk, hem doğrudan hem de dolaylı olarak sinir-kas kontrolüne etki etmektedir. Eklem pozisyon duyusundan beklenen öğrenmenin kötüleşmesi ya da bozulması direk etkisini oluşturuken; kassal yorgunluğun, eklem kinestezi ve pozisyon hissi değişiklikleri sonucu eklem gevşekliğine neden olması dolaylı etkiyi oluşturmaktadır $(30,43,44,61)$. Bu bağlamda kas yorgunluğunu, stabilite ve denge becerilerini etkileyen önemli bir faktör olarak ifade edebiliriz. Gerçekleştirilen birkaç araştırmada, egzersizin tipine, süresine ve şiddetine bağlı olarak ortaya çıkan yorgunluğun postural stabiliteyi kötüleştirdiği desteklemektedir (29, 30, 32-35). Sporla ilişkili mevcut postural stabilite çalışmaları incelendiğinde; farklı yapıdaki egzersiz üzerine postural salınımın etkileri değerlendirilmiş; (1) kısa süreliyoğun egzersizlerin daha dikkat çekici ventilasyona ve buna bağlı olarak postural salınımda daha fazla artışa ancak daha hızlı düzenlemelere, (2) uzun süre devam eden orta şiddetteki egzersizlerin daha şiddetli yorgunluğa ve buna bağlı 
olarak postural salınımda daha hafif artışa ve daha yavaş ayarlamalara ve (3) sıçrama içeren egzersizlerin yoğun proprioseptif uyarıma ve buna bağlı olarak postural salınımda oldukça fazla artışa ve yavaş düzenlemelere neden olduğu saptanmıştır. İfade edilen bu egzersiz çeşitlerine bağlı olarak stabilite kontrolünde meydana gelen azalma, vücut segmentleri üzerinde hareket eden kasların fonksiyonlarında "hata"nın ortaya çıkma durumunu da artmaktadır. Bu "hata" ligament, tendon ya da kaslarda incime ve burkulmaya neden olabilmektedir (62). Ayrıca bu egzersizler bisiklet, yürüme ve koşma gibi temel egzersizlerle sınırlı tutulmuştur. Egzersiz sonrası denge değerlerindeki bozulmanın fizyolojik mekanizması üzerine araştırmalar çoğunlukla egzersizin neden olduğu yorgunluk üzerine etkilerine odaklanılmış (1, 17, 18, 20-22), ancak diğer faktörlerin katkısı üzerine yanıtlanmamış birçok soru bulunmaktadır. Postural salınım arttıkça yaralanma riskinin artması arasındaki ilişki sunulmuştur, ancak spor sonrası postural stabilitenin bozulan etkisinin spor performansı üzerine etkisine dair bilgi eksikliğinin olduğu ifade edilebilir.

\section{TEŞEKKÜR}

Bu derleme makalesinin yazımı sırasında verdiği destekten dolayı Yrd. Doç. Dr. Hakan Katırcı'ya teşekkür ederiz. Bu derleme çalışması, ANADOLU UNI./BAP 1001 S40 kod numaralı proje kapsamında yapılmıştır.

\section{KAYNAKLAR}

1. McKenna, M.J. Mechanisms of Muscle Fatigue. In Physiological bases of sport performance. Eds: Hargreaves, M. And Hawley, J. McGraw-Hill, New South Wales, 2003.

2. Gandevia, S.C. Spinal and supraspinal factors in human muscle fatigue. Physiol Rev., 81:1725-89, 2001.

3. Bizid, R., Margnes, E., François, Y., Jully, J.L., Gonzalez, G., Dupui, P., Paillard, T. Effects of knee and ankle muscle fatigue on postural control in the unipedal stance. Eur J Appl Physiol,106:375-380, 2009.

4. Lundin TM, Feuerbach JW, Grabiner MD. Effect of plantar flexor and dorsiflexor fatigue on unilateral postural control. J Appl Biomech, 9:191-201. 1993.

5. Harringe, M., Halvorsen, K., Renstrom, P., \& Werner, S. Postural control measured as the center of pressure excursion in young female gymnasts with low back pain or lower extremity injury. Gait \& Posture, 28(1), 38-45, 2008.

6. Johnston, R., Howard, M.E., Cawley, P.W., Lossee, G.M. Effect of lower extremity muscular fatigue on motor control performance. Med Sci Sports Exerc, 30: 1703-07, 1998.

7. Trop, H. Pronator muscle weakness in functional instability of the ankle joint. Int J Sports Med, 7:291-294, 1986.

8. Schieppati, M., Hugon, M., Grasso, M., Nardone, A., Galante, M. The limits of equilibrium in young and elderly normal subjects and in Parkinsonians. Electroencephalogr Clin Neurophysiol 93:286-298, 1994.

9. Dietz, V. Human neuronal control of automatic functional movements: interaction between central programs and afferent input. Physiol Rev 72:33-69, 1992.

10. Holtzhausen, L.M, Noakes, T.D. The prevalence and significance of post- exercise (postural) hypotension in ultramarathon runners. Med Sci Sports Exerc 27:1595-1601, 1995.

11. Douglas, P.S, O'Toole, M.L., Hiller, W.D, Hackney, K., Reichek, N. Cardiac fatigue after prolonged exercise. Circulation 76:12061213, 1987.

12. Douglas, P.S., O'Toole, M.L., Katz, S.E. Prolonged exercise alters cardiac chronotropic responsiveness in endurance athletes. J Sports Med Phys Fitness 38:158-163, 1998.

13. Rifai, N., Douglas, P.S., O'Toole, M., Rimm, E., Ginsburg, G.S. Cardiac troponin T and I, electrocardiographic wall motion analyses, and ejection fractions in athletes participating in the Hawaii Ironman Triathlon. Am J Cardiol 83:1085-1089, 1999.

14. Whyte, G, Lumley, S., George, K., Gates, P., Sharma, S., Prased, K., McKenna, W.J. Physiological profile and predictors of cycling performance in ultra-endurance triathletes. J Sports Med Phys Fitness 40:103-109, 2000.

15. Ginsburg,. GS, O'Toole, M., Rimm, E., Douglas, P.S., Rifai, N. Gender differences in exercise-induced changes in sex hormone levels and lipid peroxidation in athletes participating in the Hawaii ironman triathlon. Ginsburg-gender and exercise-induced lipid peroxidation. Clin Chim Acta 305:131-139, 2001.

16. Laursen, P.B., Rhodes, E.C., Langill, R.H., McKenzie, D.C. Taunton JE Relationship of exercise test variables to cycling performance in an ironman triathlon. Eur J Appl Physiol, 87:433-440, 2002.

17. Ledin, T., Fransson, P.A., Magnusson, M. Effects of postural disturbances with fatigued triceps surae muscles or with $20 \%$ additional body weight, Gait Posture 19:184-193, 2004.

18. Vuillerme, N., Danion, F., Forestier, N., Nougier, V. Postural sway under muscle vibration and muscle fatigue in humans, Neurosci. Lett. 333:131-135. 2002a.

19. Caron, O. Effects of local fatigue of the lower limbs on the postural control and posture stability in standing posture. Neurosci. Lett. 340, 83-86, 2003.

20. Vuillerme, N., Burdet, C., Isableu, B., Demetz, S. The magnitude of the effect of calf muscles fatigue on postural control during bipedal quiet standing with vision depends on the eye-visual target distance. Gait Posture, 24, 166-172. 2006.

21. Vuillerme, N., Demetz, S. Do ankle foot orthoses modify postural control during bipedal quiet standing following a localized fatigue of the ankle muscles? Int. J. Sports Med., in press, 2007.

22. Vuillerme, N., Nougier, V. Effect of light finger touch on postural sway after lower-limb muscular fatigue. Arch. Phys. Med. Rehab. 84, 1560-1563, 2003.

23. Yaggie, J.A., McGregor, S.J. Effects of isokinetic ankle fatigue on maintenance of balance and postural limits. Arch Phys Med Rehabil, 83: 224-28, 2002.

24. Gribble, P.A., Hertel J. Effect of lower-extremity muscle fatigue on postural control. Arch Phys Med Rehabil. 85: 589-92, 2004.

25. Miura, K., Ishibashi, Y., Tsuda, E., Okamura, Y., Otsuka, H., Toh, S. The Effect of Local and General Fatigue on Knee Proprioception.In Arthroscopy. 20:(4), 414-418, 2004. 
26. Nardone, A., Tarantola, j., Galante, M., Schieppati, M. Time couse of stabilimetric changes after a strenuous treadmill exercise. Arch Phys Med Rehabil, 79: 920-4,1998.

27. Ochsendorf, D.T., Mattacola, C.G., Arnold, BL. Effect of orthotics on postural sway after fatigue of the plantar flexors and dorsiflexors. J Athl Train. 35:26-30, 2000.

28. Carson, J.S., Frank, J.E., Shapiro, R. Effects of prolonged activity on vertical jump performance. Paper presented at: 24th Annual Meeting of the American Society of Biomechanics; Chicago, IL. 7:19, 2000

29. Nardone, A., Tarantola, j., Galante, M., Schieppati, M. Fatigue effect on body balance. Electroencephalogr Clin Neurophysiol, 105:309-20,1997.

30. Lepers., R, Bigard., AX, Diard., JP, Gouteyron, J.F, Guezennec, C.Y. Posture control after prolonged exercise. Eur J Appl Physiol 76:55-61, 1997.

31. Derave, W., Tombeux, N., Cottyn, J., Pannier, J. L., \& De Clercq, D. Treadmill exercise negatively affects visual contribution to static postural stability. Int J Sports Med, 23, 44-49, 2002

32. Gauchard, G.S, Gangloff, P., Vouriot, A., Mallie, J.P., Perin, P.P. Effects of exercise-induced fatigue with and without hydration on static postural control in adult human subjects. Int J Neurosci 112:1191-1206, 2002.

33. Nagy, E., Toth, K., Janositz, G., Kovacs, G., Feher-Kiss, A., Angyan, L., Horvath, G. Postural control in athletes participating in an ironman triathlon. Eur J Appl Physiol. 92: 407-413, 2004.

34. Yaggie, J., Armstrong, W.J. Effects of lower extremity fatigue on indices of balance. J Sport Rehabil.13:312-322, 2004.

35. Zemková, E., Kyselo vičová, O., Hamar, D. Postural Sway Response To Rebound Jumps Of Different Duratıon. Human Movement, $11(2), 153-156,2010$.

36. Walsh, L.D., Hesse, C.W., Morgan, D.L., Proske, U. Human forearm position sense after fatigue of elbow flexor muscles, J. Physiol. 558:705-715, 2004

37. Corbeil, P., Blouin, J.S., Bégin, F., Nougier, V., Teasdale, N. Perturbation of the postural control system induced by muscular fatigue, Gait Posture, 18. 92-100. 2003.

38. Harkins, K.M, Mattacola, C.G., Uhl, T.L., Malone, T.R., McCrory, J.L. Effects of 2 ankle fatigue models on the duration of postural stability dysfunction. J Athl Train. 40(3):191-194, 2005.

39. Gosselin, G., Rassoulian, H., Brown, I. Effects of neck extensor muscles fatigue on balance. Clinical Biomechanics. 18:473-479, 2004.

40. Salavati, M., Moghadam, M., Ismaeil Ebrahimi I, Arab, A.M. Changes in postural stability with fatigue of lower extremity frontal and sagittal plane movers. Gait Posture. 26:214-8, 2007.

41. Schieppati, M., Nardone, A., Schmid, M. Neck muscle fatigue affects postural control in man. Neuroscience. 121:277-85, 2003.

42. Vuillerme, N., Forestier, N., Nougier, V. Attentional demands and postural sway: the effect of the calf muscles fatigue, Med. Sci. Sports Exerc. 34:1907-1912, 2002b.

43. Seliga, R., Bhattacharya, A., Succop, P., Wickstrom, R., Smith, D.,Willeke, K. Effect of work load and respirator wear on Postural stability, heart rate, and percieved exertion. Am Ind Hyg Assoc. J. 52(10):417-22, 1991.

44. Rozzi, S., Yuktanandana, P., Pincivero, D., Lephart, S. Role of fatigue on proprioception and neuromuscular control. In: Lephart S and Fu FH, Ed. Proprioception and Neuromuscular Control in Joint Stability. Human Kinetics Publishers Inc. 375-83, 2000.

45. Dickin, D. C. Doan, J. B. Postural stability in altered and unaltered sensory environments following fatiguing exercise of lower extremity joints. Scand J Med Sci Sports, 18: 765-772, 2008.

46. Cetin, N., Bayramoglu, M., Aytar, A., Surenkok, O and Yemisci, O.U. Effects of Lower-Extremity and Trunk Muscle Fatigue on Balance, The Open Sports Medicine Journal, 2, 16-22, 2008.

47. Michael, L., Madigan Bradley, S., Davidson Maury, A. Nussbaum Postural sway and joint kinematics during quiet standing are affected by lumbar extensor fatigue. Human Movement Science 25:788-799, 2006.

48. Hashiba, M. Transiet change in standing posture after linear treadmill locomotion. Jpn J Physiol., 48, 499-504, 1998.

49. Zemková, E., \& Hamar, D. Postural sway response to exercise bouts eliciting the same heart rate with different energy yield from anaerobic glycolysis. Medicina Sportiva, 7(4), 135-139, 2003.

50. Adlerton, A.K., Moritz, U., Moe-Nilssen, R. Forceplate and accelerometer measures for evaluating the effect of muscle fatigue on postural control during one-legged stance. Physiother Res Int. 8(4): 187-199, 2003.

51. Crowell, D.H., Guskiewicz, K.M., Prentice, W.E., Onate, J.A. The effect of fatigue on postural stability and neuropsychological function. J Athl Train. 36(suppl 2):S-33, 2001.

52. Zachary, G., Fox Jason, P., Mihalik, J. Troy Blackburn, Claudio L. Battaglini, Kevin M. Guskiewicz. Return of Postural Control to Baseline After Anaerobic and Aerobic Exercise Protocols. Journal of Athletic Training. 43(5):456-463, 2008.

53. Hunter, I. W., \& Kearney, R. E. Respiratory components of human postural sway. Neurosci Lett, 25(2), 155-159, 1981.

54. Jeong, B. Y. Respiration effect on standing balance. Arch Phys Med Rehabil, 72, 642-645, 1991.

55. Bouisset, S., \& Duchene, J. Is body balance more perturbed by respiration in seating than in standing posture? NeuroReport, $\mathbf{5}$, 957-960, 1994.

56. Sakellari, V., Bronstein, A. M., Corna, S., Hammon, C. A., Jones, S., \& Wolsley, C. J. The effects of hyperventilation on postural control mechanisms. Brain, 120, 1659-1673, 1997.

57. Zemková, E., Hamar, D. Postural Sway and Cardiorespiratory Response to Resistance Exercises. Physical Education and Sport Vol. 7, No 2, pp. $181-187,2009$.

58. Schmidt, R.A. A schema theory of discrete motor skill learning. Psychol. Rev. 82, 225-260, 1975.

59. Taylor, J.L., Butler, J.E., Gandevia, S.C. Changes in muscle afferents, motoneurons and motor drive during muscle fatigue. Eur. J. Appl. Physiol. 83, 106-115, 2000.

60. Pwers, S.K., Howley, Eds. Exercise physiology: Theory and application to fitnes and performance. Dubuque(IA): Brown and Bencmark Publishers; 1990.

61. Forestier, N., Teasdale, N., Nougier, V. Alteration of the position sense at the ankle induced by muscular fatigue in humans. Med Sci Sports Exerc. 34(1): 117-22, 2002

62. Mikołajec, K., and Rzepka, K. Objective Assessment and Importance of Stability and Motor Control in Sports Performance. Journal of Human Kinetics.18, 135-140, 2007. 